\title{
Estrategias para fomentar actitudes interculturales positivas en el aula
}

Gloria Rojas Ruiz

Profesora de la Facultad de Ciencias de la Educación y Humanidades Universidad de Granada. Campus de Melilla

\section{El profesorado y la diversidad cultural}

En nuestro país, al igual que en el resto de los países desarrollados, las situaciones de contacto de culturas que origina la inmigración en los centros educativos, han sido unos de las principales causas de la preocupación por los principios de la Educación Intercultural. La incorporación de alumnos de diferentes orígenes culturales, con distintas lenguas y costumbres, hace que el profesorado deba plantearse nuevas actitudes y estrategias metodológicas ante su grupo-clase para evitar posibles situaciones de discriminación o desventajas educativas.

La pregunta fundamental es saber si la escuela es capaz de asumir la responsabilidad de dar una respuesta adecuada a esta diversidad del alumnado. Lo que es evidente es que la institución escolar por si sola no es capaz de completar un proyecto pedagógico intercultural, sino que necesita de un proyecto social global en el que la interculturalidad no quede ceñida al ámbito escolar y que se aporten ideas y acciones desde todos los ámbitos de gestión y trabajo de la sociedad (MEC, 1996). Siguiendo a Aguado (1997) la influencia de la multiculturalidad se refleja en el sistema educativo, pero aunque las acciones en el ámbito de la educación formal son necesarias, no son suficientes para pasar de la coexistencia a la convivencia intercultural.

Por otra parte, los profesionales de la docencia debemos contar, como una de las premisas básicas para que la educación funcione correctamente, con la participación de todos los miembros de la comunidad educativa en el proceso formativo y la necesidad de interrelación y comunicación entre el centro educativo y el entorno que le rodea. Para que la respuesta educativa sea completa es necesario que haya una total coordinación entre los profesionales de la enseñanza, las familias y el entorno cultural y social 
que rodea al centro escolar, puesto que la educación actual exige una preparación suficiente para que el alumno forme parte de una sociedad variada y plural.

Por este motivo anterior, la demanda del profesorado sobre formación en temas de educación intercultural es cada vez más frecuente, ante la asistencia a las aulas de alumnos provenientes de culturas diferentes. Los sistemas educativos vigentes deben dar respuesta adecuada a estas peticiones y las disposiciones legales sobre temática de formación en Educación Intercultural, aunque en aumento, son todavía muy escasas. Por esto, es normal el temor de los docentes al trabajar en aulas con alumnos de distintos orígenes culturales, ya que su preparación pedagógica en estos temas durante el proceso de formación inicial es escasa o nula. Para ayudar a eliminar estos problemas, son varias las universidades españolas que introducen materias sobre Educación Intercultural en los planes de estudio de los futuros maestros; la Facultad de Educación y Humanidades de la Universidad de Granada, en el Campus de Melilla, es un claro ejemplo de esto. puesto que incorpora materias como Currículum Intercultural (asignatura de carácter obligatorio para las especialidades de Educación Infantil y Educación Primaria), Educación para la Paz (carácter optativo) en los estudios de Magisterio, o Diseño y Desarrollo de Programas Educativos Interculturales, como obligatoria en la licenciatura de Psicopedagogía.

Para ello, una de las más importantes pautas de acción que nuestra escuela actual nos ofrece es la posibilidad de modificar el currículum escolar para poder incorporar los contenidos referidos a la Educación Intercultural, llegando a convertir esta reflexión en seña de identidad y eje central de los planes institucionales del centro.

\section{El profesorado y las estrategias para fomentar valores positivos en el aula}

No es tarea fácil concienciar al profesorado en la introducción de estrategias para fomentar actitudes positivas interculturales dentro de la organización habitual de la clase. Está generalizada la idea de que el tiempo empleado en la realización de estas actividades es tiempo "perdido" de los programas de las áreas curriculares tradicionales; por este motivo, los planes de formación permanente del profesorado ya emplean parte de sus objetivos en el asesoramiento sobre la introducción de contenidos sobre valores dentro de los planes de centro y, más concretamente, en las programaciones de aula.

La actitud positiva de los docentes hacia los valores y las acciones promulgadas por la Educación Intercultural son imprescindibles para llevar a cabo dichas actividades, puesto que los profesores son los verdaderos guías de la clase. los encargados de organizar a los alumnos, de programar las estrategias, de moderar, de ayudar a la regulación de los conflictos y de preparar un motivador y acogedor ambiente de clase. Siguiendo a Cabrera y otros (1999), el profesorado da sentido al cambio cuando lo fundamenta en su propio conocimiento práctico y personal, asi como en su propia experiencia.

El MEC (1992), sugiere que el papel del docente en el ejercicio de estas estrategias ha de basarse en las siguientes cualidades: 
1. Autenticidad, coincidiendo lo que dice con lo que hace. No tiene sentido ni utilidad pedagógica que un profesor promulgue actitudes antirracistas, si su comportamiento en el aula demuestra que no es capaz de aceptar y trabajar con la diversidad cultural de la misma.

2. Competencia para afrontar situaciones conflictivas en el aula. Para ello, es básico que el profesor se forme previamente en las estrategias de regulación de los conflictos. Conocer y llevar a cabo actividades sobre negociación, escucha activa, empatía o mediación es imprescindible para lograr un buen clima, no sólo en las relaciones de aula, sino de todo el centro y la comunidad educativa en general.

3. Aceptación incondicional de sus propios alumnos, considerándolos, desde un primer momento, como personas dignas de todo respeto y consideración. Ridiculizar o avergonzar a los alumnos desde edades muy tempranas, favorece la aparición de una autoestima deteriorada.

4. Comprensión y confianza. Son cualidades muy dependientes de la anterior; el docente deberá ser capaz de comprender el mundo infantil y adolescente y la confianza hacia sus alumnos será la consecuencia más inmediata de este proceso.

5. Estímulo recíproco entre alumnos-profesores, en las diferentes y numerosas experiencias didácticas.

6. Trabajo cooperativos que favorezcan las relaciones entre diferentes personas, ayudando a eliminar posibles estereotipos previos.

La asimilación y el cumplimiento de todas estas características suponen una modificación de los métodos didácticos y una nueva forma de entender la enseñanza, destinada no sólo a transmitir conocimientos conceptuales, sino también preparada para la formación del desarrollo integral del alumno, basándose en el énfasis en el proceso didáctico, el aprendizaje significativo y el aprendizaje cooperativo (Yus, 1996).

Una vez que los profesores han decidido incorporar en su planificación del aula las estrategias para fomentar actitudes interculturales positivas, se plantean una cuestión fundamental: ¿cuál es la edad idónea para comenzar a realizar estas actividades con los alumnos? Son muchas las opiniones sobre la respuesta a este interrogante. Algunos especialistas creen que la etapa de Educación Infantil no es la más conveniente para comenzar a trabajar valores como la solidaridad o el antirracismo; basan su teoría en la creencia de que a una edad tan temprana no se manifiestan actitudes interculturales negativas, por lo que lo más apropiado es esperar a que surjan conflictos para intervenir. Sin embargo, la mayoría de los profesionales en educación en valores, consideran que esta etapa educativa es la mejor para la incorporación de actividades relacionadas con las actitudes y valores promulgadas por la Educación Intercultural, puesto que, muchos estudios demuestran que los niños cuando se escolarizan (3-4 años), ya se incorporan a la escuela con ciertas experiencias de socialización y una determinada identidad cultural y a los cinco, pueden presentar actitudes de rechazo hacia miembros de otros grupos (Aguado, 1995 y Jordán, 1997). Estos datos justifican la intervención didáctica temprana en la formación de actitudes interculturales de los alumnos, evitando, en la medida de lo posible, la futura aparición de valores contrarios a los promovi- 
dos por la Educación Intercultural. No obstante, la mayoría de los docentes de cursos superiores consideran que es en la etapa de Educación Secundaria Obligatoria donde aparecen los conflictos más difíciles de resolver, coincidiendo con la etapa de pre-adolescencia y la adolescencia. Como es bien sabido, es un periodo evolutivo en el que se produce un replanteamiento y una reestructuración de los valores, por lo que la influencia de los profesores, uno de los tres grandes agentes socializadores, junto con la familia y los amigos, es bastante grande. Aula Práctica Primaria (2001) considera que es importante que los docentes transmitan a los alumnos la idea de que los valores constituyen una parte imprescindible de su existencia y de que vean los valores de los profesores como posibles alternativas, no como los únicos correctos y válidos. Para llevar a cabo este proceso, es necesaria la intervención y la implicación de todos en el desarrollo de estrategias eficaces para cultivar actitudes positivas hacia los valores de solidaridad, tolerancia, respeto, etc.

Siguiendo a Hernando $(1997,90)$ para que las estrategias que se trabajen desde los centros educativos sobre educación en valores tengan éxito, debe presentar las siguientes características:

- Deben estar basadas en el mayor respeto hacia el educando.

- Deben servir como base transformadora el clima del colegio y de la familia.

- Deben estar adaptada a las características psicosociales de la persona.

- Debe incidir en la capacidad de conocimiento y razonamiento para que la persona sea capaz de discernir y promover el cambio en su conducta.

Reyzábal y Sanz $(1995,31)$ sugieren que, a la hora de trabajar actividades sobre los contenidos de los temas transversales, es fundamental provocar situaciones en las que el alumno pueda:

- Plantearse y analizar problemas o acontecimientos que entrañen conflictos de valor.

- Debatir libre y racionalmente acerca de ellos, manifestando las propias opiniones y respetando a las personas que tengan otras.

- Confrontar los propios principios con los de los compañeros, los de nuestra cultura con los de otras, los de distintas épocas históricas, los de nuestra religión con otras religiones o con concepciones filosóficas y científicas diversas.

- Saber defender la posición que se considere más justa aun cuando no resulte cómodo.

Sánchez y Mesa (2002) sugieren que introducir actividades para fomentar actitudes positivas hacia la diversidad cultural en el aula supone modificar algunos planteamientos tradicionales de los docentes y tener en cuenta aspectos como la necesidad de que los docentes se impliquen de forma muy activa en la realización de estas actividades, transmitiendo una idea de continuidad en las mismas y no como simples recuerdos de determinadas efemérides (Día de la Paz, de la Mujer Trabajadora, etc.). Por otra parte, como aspecto interesante a resaltar, aconsejan el asesoramiento de los especialistas en orientación para el desarrollo de los contenidos sobre Educación en Valores y la creación de algún órgano de seguimiento de las actividades, como la Comisión de Coordinación Pedagógica, o una comisión del Consejo Escolar del centro. 


\subsection{Campos de estudio sobre actividades interculturales}

Los campos de trabajo sobre actividades para fomentar actitudes interculturales positivas se centran en tres ámbitos fundamentales (Sánchez y otros, 2000):

1. Realización de actividades interculturales en el centro.

2. Realización de actividades interculturales en el aula.

3. Formación del profesorado en Educación Intercultural.

El objetivo principal de la organización de las actividades dentro del centro, es intentar implicar y concienciar a todos los miembros de la comunidad educativa en la necesidad y participación de las mismas. Se requiere de forma imprescindible la participación de los padres en las mismas para hacerles reflexionar en la necesidad de establecer una adecuada coordinación padres-escuela sobre la educación en valores. En muchas ocasiones existen grandes diferencias entre las actitudes y principios que se promulgan desde la escuela y los que se fomentan en las familias y en otros sectores sociales (p.e., la gran influencia que ejercen sobre los niños y adolescentes los medios de comunicación), lo que dificulta el proceso de asimilación de los mismos. Desde este trabajo, promulgamos el tratamiento educativo de los valores como uno de los temas prioritarios desde las Asociaciones de Padres y Madres y desde las Escuelas de Padres, tan escasas en algunas zonas del ámbito nacional.

Algunas estas actividades relacionadas con los contenidos que tratamos son: exposiciones, juegos cooperativos, cinefórums, teatro y cine (realización de cortos), contactos e intercambios con alumnos de otros centros, a través de cartas o correo electrónico, etc.

Las actividades dentro del aula se tratan desde tres perspectivas diferentes:

- Introducción de los contenidos interculturales y para la paz desde una perspectiva de transversalidad: incorporados en las unidades didácticas y adaptados a las diferentes áreas curriculares.

- Actividades para las relaciones grupales: dinámicas de autoestima, conocimiento, comunicación y escucha activa. Para comenzar a hablar de tolerancia y respeto, es necesario fomentar el respeto por uno mismo y el saber escuchar, dialogar y comunicarse con los demás.

- El uso de Estrategias Sociomorales y Estrategias Sociafectivas en la educación en valores. El objetivo de las primeras es que los alumnos tomen conciencia de sus propios valores, para reflexionar y profundizar en ellos. Como ejemplos: Clarificación de Valores, Dilemas Morales, Resolución de Conflictos o Lectura de Imágenes. El planteamiento de las estrategias socioafectivas es el de considerar que para provocar un cambio de actitudes en los alumnos, es necesario que éstos "vivan y sientan" situaciones de discriminación, situándose en el lugar del otro.

La formación del profesorado en Educación Intercultural es básica para llevar a buen término los objetivos propuestos por la misma. Si embargo, esta preparación no ha de ir dirigida exclusivamente a los docentes, sino que todos los miembros de la comunidad educativa son piezas claves para conseguir una adecuada atención a la diversidad cultural presente ya en nuestros centros escolares. 
Es evidente que se necesita un nuevo modelo de formación del profesorado que lo prepare para los retos que trae consigo la Educación Intercultural y, como se ha comentado en apartados anteriores, la legislación europea sobre estos aspectos es todavía muy escasa. Por esto, es imprescindible trabajar, tanto desde la formación inicial como desde la permanente, materias y proyectos relacionados con los contenidos de la Educación para la Paz y la Educación Intercultural.

\section{Sugerencias y actividades para trabajar educación intercultural en el centro y aula}

La producción de la literatura sobre Educación Intercultural ha aumentado en los últimos años, tanto en ámbitos nacionales como internacionales, debido a los motivos expuestos durante los anteriores apartados de este trabajo. La mayoría de las actividades que se sugieren en los materiales editados para trabajar los contenidos multi e interculturales en el aula y centro educativo, se introducen dentro de las propuestas sobre Educación en Valores y fundamentalmente en las programaciones de los contenidos de los Temas Transversales. El objetivo de esta última parte es exponer una breve relación de dichas estrategias, publicadas en diversos materiales educativos. La bibliografía citada

En las Cajas Rojas de los Temas Transversales editados por el MEC (1992), las propuestas sobre Educación Intercultural están englobadas dentro del bloque de componentes de Educación para la Paz; otros autores consideran que el tema intercultural posee tanta importancia y tanta temática propia que merece ser considerado como un eje transversal en sí mismo. El MEC (1992) en el material referido para la sugerencia de actividades organiza dos partes diferenciadas: implicación de todo el centro y actividades concretas del aula, introducidas en las unidades didácticas. Dentro del primer bloque, entre otras, se proponen la realización de Campañas de Solidaridad, Correspondencia Interescolar e Intercambios y Juegos Cooperativos. Para las acciones en el aula y, basándose en la metodología sociafectiva, se sugiere llevar a cabo Estudios de Casos, Técnicas de Clarificación de Valores, Análisis de Conflictos, Juegos de Rol y Juegos de Simulación.

Reyzábal y Sanz (1995) para trabajar Educación en Valores, apuestan por la realización de actividades sobre Dilemas Morales, Análisis Crítico, Coloquios a partir de Textos, Clarificación de Valores y Dramatizaciones o Simulaciones de situaciones reales o ficticias. Yus (1996) coincide en algunas de las propuestas anteriores y amplía sus sugerencias para la Educación en Valores en actividades sobre Comprensión Crítica (Diálogos a partir de un Texto, Confrontación y Análisis de Valores), Clarificación de Valores (Diálogos Clarificadores, Hojas de Valores, Frases Inacabadas...). Ejercicios Autoexpresivos (Hojas de Pensamiento. Producciones). Dilemas Morales; actividades de Autorregulación (Autoobservación, Aturrefuerzo...), Debates o estrategias de Modificación de Conducta. Jordán (1996) concreta su ámbito de actuación en el fomento de actitudes positivas hacia la interculturalidad, proponiendo la alternancia en el aula de Estrategias Sociomorales y Estrategias Socioafectivas. Dentro de las primeras propone, en la misma 
línea que los autores anteriores, la realización de Clarificación de Valores, Comprensión Crítica, Discusión de Dilemas Morales y ejercicios de Autorregulación y Autocontrol. Dentro de las Socioafectivas, sugiere la actividad denominada El Restaurante del Mundo, como ejemplo claro de este tipo de estrategias.

Hernando (1996) divide las técnicas propuestas para la Educación en Valores, en tres apartados: las que se adaptan a cualquier asignatura del currículum, las idóneas para trabajar en horas de tutoría y las técnicas para el conocimiento del grupo, en las que pretende orientar al tutor en dinámicas para conocer al grupo con el que se quiere trabajar. Sobre el primer apartado, la autora sugiere actividades para introducir dentro de la organización de la clase en diferentes áreas curriculares, partiendo de la idea de que no hay materias más idóneas que otras para trabajar el ámbito de los valores. Para las técnicas indicadas en las sesiones de tutoría, coincide con otras propuestas en la sugerencia sobre la puesta en práctica de Clarificación de Valores, Dilemas Morales y Juegos de Simulación, pero aporta e/ aprendizaje de los pasos sobre Resolución de Conflictos como base para el ejercicio de actitudes democráticas y tolerantes.

Pérez Serrano (1997) engloba sus sugerencias dentro del objetivo de una educación para la democracia y divididas en diversos bloques (Educación Moral, Educación para la Convivencia y la Tolerancia y Educación para la Paz]. Para dichos apartados recomienda algunas de las actividades ya comentadas anteriormente, como la Clarificación de Valores, los Dilemas Morales, las Hojas de Valores, el Role Playing o la Resolución de Conflictos.

Paniego y Llopis (1998) centran su trabajo en la sugerencia de actividades adecuadas para educar a los alumnos en la solidaridad, a través de la Práctica de la Lectura (P.e., textos sobre prejuicios), Juegos Cooperativos, Técnicas de Comunicación, Juegos de Rol o Tomas de Decisiones Consensuadas.

Otros autores, como Essomba (1999) o Arroyo (2000) toman como base para sus propuestas educativas los objetivos y contenidos promulgados por la Educación Intercultural, para la elaboración de proyectos curriculares y unidades didácticas en las diferentes áreas del currículum.

Lucini (2000) destaca la importancia del profesor como modelo de identificación personal para el alumno, especialmente en las etapas de infantil y preadolescencia. Por este motivo, el docente que se comprometa en la defensa de los valores promovidos por los Temas Transversales en general, ha de comprometerse con la mejora de su propia ética personal. En el mismo material, el autor contempla tres formas de introducir los contenidos de la transversalidad en las actividades de aula:

a) Integrar los contenidos organizada y coherentemente dentro de las programaciones de las áreas curriculares, lo que debería ser una práctica habitual en las actividades del aula.

b) Organizar situaciones especiales de aprendizaje relacionadas con los valores promovidos por los Temas Transversales, como la creación de una "Semana Intercultural", con la intervención de toda la comunidad educativa. Es imprescin- 
dible que estas actividades no queden como "actuaciones fuera de contexto", sino que deben ser parte de un proceso continuo de los propósitos del centro educativo sobre educación en valores.

c) La última propuesta es la más innovadora y la que supondría un giro más radical en los planteamientos educativos tradicionales de los docentes: organizar un área curricular en torno a un Tema Transversal. Por ejemplo, ir elaborando los contenidos del área de Historia desde el punto de vista de la igualdad de oportunidades de ambos sexos, o desde la perspectiva de la Educación Intercultural.

Cid y otros (2001) plantean su propuesta de estrategias para el fomento de actitudes positivas desde los principios de los Temas Transversales, sugiriendo técnicas concretas para el trabajo en el aula de educación moral y en valores. El siguiente cuadro esquematiza las sugerencias prácticas de estos autores:

\begin{tabular}{|c|c|}
\hline Métodos de autoconocimiento y clarificación de valores & $\begin{array}{l}\text { - Ejercicios de frases inacabadas } \\
\text { - Preguntas esclarecedoras } \\
\text { - Hojas de valores } \\
\text { - Ejercicios autoexpresivos } \\
\text { - Ejercicios autobiográficos }\end{array}$ \\
\hline Estrategias para el desarrollo del juicio moral & $\begin{array}{l}\text { - Discusión de dilemas morales } \\
\text { - Diagnóstico de situaciones }\end{array}$ \\
\hline $\begin{array}{l}\text { Estrategias para el desarrollo de la capacidad } \\
\text { de toma de perspectiva social y empatía }\end{array}$ & $\begin{array}{l}\text { - Role-playing } \\
\text { - Role-model }\end{array}$ \\
\hline Estrategias para la comprensión crítica de la realidad & $\begin{array}{l}\text { - Diálogos a partir de un texto } \\
\text { - Escribir para comprender críticamente }\end{array}$ \\
\hline $\begin{array}{l}\text { Enseñanza de habilidades para } \\
\text { el diálogo y la comunicación }\end{array}$ & $\begin{array}{l}\text { - Ejercicios de capacidades dialógicas: } \\
\text { saber escuchar y expresar, respeto, análisis } \\
\text { de alternativas... }\end{array}$ \\
\hline Adquisición-aprendizaje de habilidades sociales & $\begin{array}{l}\text { - Técnicas para la resolución de conflictos } \\
\text { - Autorregulación y autocontrol: ejercicios en los } \\
\text { que se necesita la participación del profesorado } \\
\text { y actividades netamente personales } \\
\text { - Role-playing }\end{array}$ \\
\hline
\end{tabular}

Cid y otros (2001) destacan la importancia de que el centro educativo reflexione sobre cómo su comunidad quiere y debe educar en valores, para complementar la eficacia de las técnicas referidas.

Esta última idea se une al uno de los planteamientos básicos del material realizado por el Aula Práctica Primaria (2001), en el que la educación en valores se sustenta en la 
implicación y participación de todo el centro (valores que han de reflejarse en el Proyecto Curricular de Centro y en el Proyecto Educativo] y no sólo en el trabajo del docente en su aula. Desde las aportaciones del Aula Práctica Primaria (2001) también se destaca el papel que el maestro debe tener en la realización de las actividades para fomentar actitudes positivas en el aula.

Además de toda la extensa bibliografía sobre las propuestas para realizar actividades en el aula y en el centro sobre Educación en Valores en general y Educación Intercultural en particular, existen numerosas páginas en Internet donde cualquier docente puede encontrar interesantes sugerencias sobre estos temas. Como ejemplo, la página EDUALTER (URL: http://www.pangea.org/edualter) en la que se informa sobre materiales, bibliografía y direcciones acerca de la Educación para la Paz, la Interculturalidad, la Educación en Valores y la Educación para el Desarrollo. También dispone de una agenda actualizada en la que se detallan los acontecimientos relacionados con la Cultura de Paz (Cursos, Congresos...). La URL: http://www.afs.intercultura.org/index.html, ofrece una serie de materiales didácticos sobre Educación Intercultural fácilmente aplicables en las diferentes etapas educativas. Las páginas de AVERROES, RED TELEMÁTICA EDUCATIVA DE ANDALUCÍA (URL: http://averroes.cec.junta-andalucia.es/www/inmigrantes/enlaces.html] y la URL: http://www.sodepaz.org/construyendolapaz, son interesantes fuentes de consulta sobre bibliografía, recursos y otros enlaces en el campo de la Educación en Valores y la Educación Intercultural.

\section{Propuestas de actividades concretas sobre educación intercultural}

De todas las sugerencias realizadas en la bibliografía expuesta, se observa una serie de actividades que se proponen de forma continuada para el trabajo de Educación en Valores (Clarificación de Valores, Dilemas Morales, Juegos de Rol...) y que, por la experiencia de ya varios años de interés por este tema, son muy eficaces, si se realizan de forma continuada en el centro y en el aula y con una planificación y participación adecuada desde la comunidad educativa. En este sentido, Sánchez y Mesa (2002) destacan algunos de los giros necesarios que el centro educativo debe dar a la hora de introducir estas estrategias en la dinámica del centro:

- Comenzar a trabajar Educación Intercultural desde la etapa de Educación Infantil.

- Implicación activa de todo el profesorado en la elaboración y desarrollo de estas actividades.

- Introducirlas en las programaciones de aula, para que sea un trabajo continuo y permanente.

- Contar con el apoyo de los especialistas en Orientación, especialmente a través de la inclusión de estas actividades en el Plan de Acción Tutorial.

- Planificar acciones en las que intervenga toda la comunidad educativa.

- Necesidad del trabajo en equipo del profesorado para lograr la efectividad de las actividades, para lo que se necesitan espacios adecuados de reunión y encuentro. 
A continuación se proponen algunas estrategias concretas para que los docentes que consulten este trabajo puedan utilizarlas en sus aulas, siempre contando con la posibilidad de adaptarlas a las características concretas de su alumnado, espacio y tiempo disponible.

\subsection{Clarificación de valores}

Son una serie de técnicas que suelen emplearse al final de un proceso continuo de realización de actividades sobre Educación en Valores, con el objetivo fundamental de que el alumno piense y reflexione sobre sus propios valores y creencias, ayudando a construir su identidad personal. Por otra parte, el docente que ha trabajado con el grupo comprueba si se han producido algunas modificaciones en las ideas de partida de sus alumnos. La forma más habitual de desarrollo de esta actividad es una realización individual, comentar en pequeños grupos y al final, puesta en común en gran grupo.

A continuación y a modo de ejemplo, se presenta una actividad sobre clarificación de valores.

\section{¿Cuáles son nuestros valores?}

\section{Objetivos}

- Trabajar el diálogo como valor fundamental entre participantes de un grupo.

- Reflexionar de forma individual y colectiva sobre los valores de los participantes.

- Compartir los valores individuales con el grupo y conocer los valores de los demás.

Participantes

Edad mínima: Adolescentes, jóvenes y adultos.

Participa todo el grupo (20 ó 25 personas).

Duración: Una hora

\section{Materiales}

Lista de frases incompletas

Papel continuo

Colores (lápices, rotuladores, acuarelas, etc.)

Recortes de prensa

Cartulinas

Pegamento

Desarrollo del juego

Se entrega a cada participante una lista de frases incompletas y se les pedirá que las completen, rápidamente y con las primeras ocurrencias que vengan a su mente; además, se les sugiere que elaboren otras frases que no están en el listado y que crean que deben estar recogidas.

Ahí fuera te están esperando para...

La mejor herencia es...

La vida es...

El amor es como...

¿Conoces realmente...?

Hombres y mujeres son... 


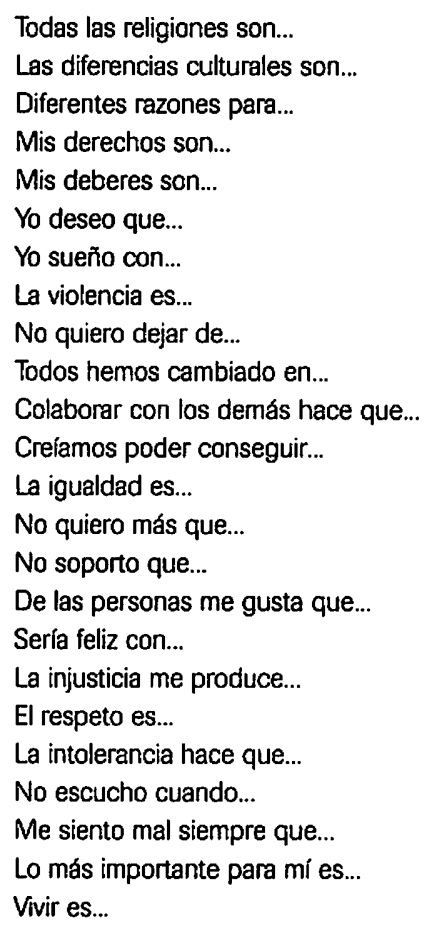

Después de completar las frases, se hace una puesta en común y se decide cuáles son las más importantes para ellos.

\section{Evaluación}

El animador el grupo, al final de la actividad, realizará preguntas como:

¿Me ha resultado difícil terminar las frases incompletas?

¿Cuál me ha resultado más difícil completar?

¿Cómo me he sentido con esta experiencia?

¿Qué respuesta de mis compañeros me ha sorprendido más?

¿Qué he aprendido con esta actividad?

¿Hay algo que no esté reflejado en ninguna de las contestaciones y considero importante?

¿Qué frase se adecua más a mi forma de pensar?

Fuente: Sánchez y Mess $(2002,112-113)$

\subsection{Dilemas morales}

La técnica de Discusión de Dilemas Morales se usa para estimular el desarrollo del razonamiento moral y se basa en los trabajos de Kolhberg sobre el juicio moral. Consiste en la presentación de una breve historia que debe provocar en los alumnos un conflicto cognitivo, en los que éstos, a través de una reflexión individual y un posterior debate con el grupo, deban decantarse por alguna de las soluciones dialogadas. Se necesita que estas historias estén relacionadas con el contexto de los estudiantes y que sean significativas 
para ellos. Uno de los grandes objetivos de esta actividad es que comprendan que un mismo dilema puede tener soluciones diferentes y que no necesariamente la postura individual tiene que coincidir con los planteamientos del resto del grupo.

A continuación se ilustra este método con un ejemplo de discusión de un Dilema Moral, recomendado para la etapa de Educación Secundaria Obligatoria (ESO).

\section{El alcalde y las chabolas}

Eres el alcalde de tu municipio y te encuentras con la siguiente situación a la que debes dar respuesta en el sentido que consideres más apropiado.

En los alrededores de un barrio existe un asentamiento chabolista cuyos pobladores llevan asentados allí varios años sin ningún tipo de infraestructura sanitaria, educativa, ni de servicios (electricidad, agua corriente, etc.). Una organización social del municipio propone que se reinstalen en viviendas dignas y para ello, ofrece la dotación gratuita de suelo para construir viviendas municipales destinada a este grupo de ciudadanos. También ofrece la posibilidad de que los destinatarios puedan contribuir a sufragar una parte de los gastos mediante su propio trabajo en las obras de construcción. El resto correria a cargo de los Presupuestos Municipales. Esta Asociación piensa que el Ayuntamiento no puede permanecer impasible ante la indigna situación que viven estas personas y que es un deber de la sociedad en general y tuyo, como alcalde. en particular, dar una respuesta que permita vivir a estos ciudadanos en condiciones humanamente dignas. Amenazan con denunciar la situación en los medios de comunicación si no se atienden sus justas reivindicaciones.

Sin embargo, la Asociación de Vecinos del barrio, junto con la Asociación de Comerciantes de la zona donde se instalarán estas viviendas, se oponen a estas medidas. En primer lugar, piensan que como en la zona existen muchos colegios y hay mucha población infantil, resultaria enormemente peligroso instalar un asentamiento así, dadas las frecuentes noticias que hay sobre tráfico de drogas y delincuencia. relacionadas con este tipo de población. Los comerciantes piensan que se verian perjudicados en sus ventas debido al aumento de la inseguridad ciudadana. Por otro lado y, dado que entre esta población hay gitanos, les parece injusto que se les den facilidades a este grupo de población, cuando el problema de la vivienda es muy acusado en todo el municipio y existen otras familias no gitanas que no reciben ninguna ayuda. Amenazan con manifestaciones masivas si no se les hace caso.

\section{Propuestas para la reflexión:}

- Haz una lista con todas las razones que se te ocurran a favor de la primera propuesta.

- Haz una lista con todas las razones que se te ocurran a favor de la segunda propuesta.

- Después de ver todas estas razones:

¿Cuál es tu decisión?

¿A quién beneficia? ¿De qué manera?

¿A quién perjudica? ¿De qué manera?

Discutir en grupos las decisiones tomadas individualmente y proponer una solución consensuada por los miembros del grupo. Dicha solución no tiene por qué ser una de las dos propuestas que aparecen en el texto, sino que el grupo puede aportar soluciones alternativas.

Si en lugar de ser el alcalde fueses uno de los chabolistas, ¿qué harías?

¿Y si fueses uno de los vecinos implicados?

¿En qué medida cambiaría tu opinión si entre los chabolistas no hubiese gitanos?

Fuente: MEC (1996, 133) 


\subsection{Juegos de rol}

El juego de rol (Role-Playing) consiste en dramatizar una situación de discriminación con la que los participantes se pueden encontrar fácilmente, tanto de forma particular, como en el contexto que le rodea. La situación que se representa debe ser de un conflicto de valores y los alumnos han de vivenciarla intelectual y afectivamente. Sólo un grupo de estudiantes lleva a la práctica dicho conflicto y el resto observa, anotando lo necesario para el debate posterior, imprescindible para el evaluación de la actividad.

Esta técnica es muy válida para ayudar a entender un problema y desarrollar la empatía, la posibilidad de ponernos y comprender la situación de los demás, por lo que favorece la cohesión del grupo. Es una de las actividades más indicadas para saber defender ideas que no necesariamente coinciden con la propia.

Para aplicarlo, se necesita que el profesor motive a su realización, puesto que, sobre todo en etapas superiores, el "sentido del ridículo" cohibe a los alumnos ante una representación teatral. El clima de libertad, de diálogo y respeto en el aula es fundamental para superar esta idea anterior.

Como se ve en el ejemplo que se expone a continuación, el esquema de trabajo es el siguiente: situación, papeles y guión de discusión. La situación de conflicto debe conocerla todo el grupo y es recomendable que los estudiantes que van a representar la situación, se preparen sus papeles con anterioridad. Hay que destacar que, aunque las líneas de actuación de los personajes van marcadas en la actividad, la improvisación de los actores es una pieza fundamental para el buen desarrollo del juego de rol.

La última parte, la discusión, es la más educativa, puesto que se ponen en común las ideas de todo el grupo sobre el tema en conflicto, los sentimientos en juego durante la actividad, cómo se han sentido y actuado los participantes, cómo se puede defender una postura que no corresponde con la propia, etc. Es muy interesante que los papeles estén cruzados (p.e., si tratamos un tema de discriminación hombre-mujer, conviene que el alumno haga el papel de chica y viceversa).

A continuación presentamos un ejemplo de Juego de Rol indicado para trabajarlo con profesores o docentes en proceso de formación, puesto que se ponen en juego conceptos como Claustro, Consejo Escolar o Comunidad Educativa. 


\section{Situación:}

Un centro de Educación Primaria recibe este curso escolar un grupo de quince alumnos, hijos de inmigrantes asentados en la ciudad. Dichos niños van a distribuirse entre el primer y el segundo ciclo de Primaria. Un reducido número de profesores, profesores, preocupados por la adecuada integración de estos niños en el centro, proponen al claustro la posibilidad de organizarles actividades de acogida, decorar alguna parte del colegio como motivos de sus países de origen y enseñar al resto de los alumnos costumbres, situación geográfica, etc.., sobre las ciudades de las que provienen sus nuevos compañeros. También desean comunicarlo al Consejo Escolar, puesto que consideran que en este tipo de actividades debe estar implicada toda la comunidad educativa. Algunos profesores más se intentan unir a la propuesta, pero, ante la negativa del director del centro, que ejerce un liderazgo autoritario, retiran el apoyo a la propuesta de sus compañeros. El director argumenta que esas actividades no son adecuadas, puesto que lo normal es que esos niños asimilen las costumbres españolas, dejando las suyas para cuando regresen a sus palses de origen. El resto de los profesores sólo se preocupa de los problemas que les va a suponer el tener en su aula, alumnos que no hablan español y no entenderán nada de lo que le expliquen.

Papeles:

- Grupos de profesores interesados en los nuevos alumnos.

- Director. negando totalmente la realización de esas actividades.

- Profesores preocupados por los problemas que conlleva tener estos niños en el aula.

- Padres de los alumnos del centro, unos a favor y otros en contra de las actividades.

- Padres de los niños inmigrantes.

Guión de discusión:

- ¿Cómo te sentirías en el caso de los profesores que proponen las actividades?

- ¿Y en el caso de los alumnos que llegan nuevos al centro?

$-i Y$ en el de sus padres?

- ¿Crees que es justa la decisión del director?

- ¿Qué harías tú si fueras el director del centro?

- ¿Conoces alguna situación de discriminación parecida?

- ¿Qué medidas crees que se puede tomar en los centros para evitar este tipo de discriminaciones?

- ¿A quién corresponde desarrollar estas medidas?. ¿Qué podemos hacer nosotros?

Fuente: Sánchez y Mesa $(2002,28]$

\subsection{Técnicas de Resolución de conflictos}

Aunque el conflicto es algo natural en las relaciones de grupo, es un concepto que generalmente va asociado a acepciones negativas. El objetivo de estas actividades es que los alumnos comprendan que el problema no es el conflicto en sí, sino la forma de resolverlos; por este motivo se pretende que los estudiantes analicen los problemas con los que normalmente se encuentran durante su vida en el centro escolar y aprendan a regularlos de forma crítica, constructiva y no-violenta. Como sucedía en el resto de las técnicas, es importante que las situaciones propuestas sean significativas para el alumno y muy relacionada con su contexto cercano.

Para llevar a cabo correctamente las técnicas de resolución de conflictos, es positivo que se experimenten con anterioridad ejercicios sobre diálogo, comunicación y escucha activa, claves para una buena regulación de los problemas.

El ejemplo de estudio de un caso que se escribe a continuación está indicado para aplicarlo a alumnos de la etapa de Educación Secundaria. 


\section{Problemas con la disciplina y algo más}

En un centro de Educación Secundaria, la mayor parte del profesorado comenta día sí y día también las faltas de disciplina del alumnado. La sala de profesores suele ser un lugar donde se escucha casi diariamente los lamentos por esta situación. Incluso también se echa en cara la falta de colaboración de las madres y padres para solucionar este problema.

Uno de los profesores que más descontento está es Sergio. profesor de Historia, con diez años de ejercicio en la profesión.

Un día, en una de sus clases, estaban abordando la situación de la inmigración. Para ello les propuso un debate sobre este tema según unas noticias de prensa sobre la vida de los inmigrantes en España. La clase iba más o menos bien, pero Sergio increpó a Álex para que diese su opinión, diciéndole algo así como que siempre está hablando y cuando debe hablar está callado. Álex está considerado como uno de los alumnos más "conflictivos" de la clase. Álex le respondió que no le importa para nada cómo viven, que se busquen la vida como quieran y si no pueden que se vuelvan para su pais, que nadie los ha llamado. Además, le replicó que estaba harto de los debates de la clase que luego no servían para nada y que eran una pérdida de tiempo. Sergio les respondió que si no quería participar y si además le parecía una pérdida de tiempo, mejor era que se fuese de clases para la Biblioteca o para el Aula de guardias (lugar donde habitualmente van los estudiantes expulsados de las clases). Álex le contestó subiendo el tono que él no tenía por qué salir de clase, que él tenía derecho a estar alif y que no podía expulsarlo por no querer participar. Sergio le respondió diciéndole que le encantan las personas que sólo piensan en los derechos y nunca en los deberes y con la misma, siguió con la clase.

Debido a este incidente. Sergio tuvo que forzar las llamadas al resto para que participasen. pero poco a poco consiguió que varios estudiantes opinasen. Al cabo de un rato, Ảlex rompió su silencio profiriendo comentarios despectivos sobre algunas de las opiniones de sus compañeros, con un inequivoco tinte racista $\mathrm{e}$ incluso insultando a alguno de los mismos. Al cabo de un rato. Sergio no aguantó más y con un tono muy encendido expulsó a Álex de la clase. Éste le contestó diciendo que no tenfa derecho a expulsarlo, que él estaba opinando. produciéndose un forcejeo verbal entre ambos.

Finaimente Álex sale de la clase. pero cuando está a punto de cerrar la puerta, se encara visualmente con el profesor y en un tono amenazador le dice: "esto lo vas a pagar muy caro. tú aún no sabes quién soy yo". Sergio continuó con la clase como pudo. aunque estaba visiblemente afectado.

Al finalizar la clase y salir del aula se encontró con Álex en el pasillo, que volvió a encararse con él, insultándolo y amenazándolo nuevamente. Sergio cogió al alumno por la cabeza y lo metió en la sala de profesores. Los docentes que estaban alli quedaron sorprendidos y Sergio les preguntó muy alterado qué se hace con un elemento como éste. que no deja dar la clase, que es un cerdo racista y un sinvergüenza que insulta a todo el mundo y aún encima tiene el atrevimiento de amenazarle delante de todos. Sin esperar respuesta, volvió a cogerlo por el jersey y lo empujó fuera de la sala de profesores. Cuando salió Álex del colegio, dijo que fue apaleado por Sergio.

Al día siguiente, los colegas de Álex y. a petición de éste, no entraron en la clase como muestra de solidaridad. El padre de Álex, que es muy crítico con el profesorado, porque piensa que hay demasiados suspensos. presenta una denuncia a la dirección por malos tratos a su hijo, haciendo constar que dependiendo de cómo se resuelva esa denuncia presentará otra en los tribunales de justicia. La dirección del centro decide cambiar a Álex de su clase hasta que se reúna el Consejo Escolar 
El caso sale en la prensa, se supone que por iniciativa del padre de Álex de la AMPA que en todo momento apoya la denuncia y en la que sale muy mal parado Sergio. Ante esa noticia, el claustro envía al día siguiente una nota de solidaridad con su compañero Sergio.

La dirección amenaza a los miembros de la antigua clase de Álex con tomar medidas como la expulsión si no entran en clase. Un sector de los estudiantes comienza a recoger firmas de apoyo a Álex. La tensión va en aumento e incluso, aparecen pintadas en el centro educativo en contra de Sergio. Ante las mismas $y$, conocida la nota de prensa, la mayoría de los estudiantes consideran que se está manchando la trayectoria profesional de Sergio que, si bien es un profesor de los "duros", siempre fue correcto en el trato con el alumnado y deciden hacer un acto de apoyo a Sergio. Reunido el Consejo Escolar decide cambiar a Álex de clase y expulsarlo durante quince días.

\section{Actividades}

1. Identifica la estructura del conflicto.

2. Análisis y valoración de la forma de encarar el conflicto por parte de Sergio y Álex.

3. Igualmente, por parte de la dirección, del claustro, de la AMPA y del padre de Álex.

4. ¿Cómo actuarías en este caso, si fueses la dirección, profesor, alumno o miembro de la AMPA?,

5. ¿Cómo consideras que es el contexto del centro en relación al afrontamiento positivo de los conflictos?

6. ¿Cómo ves el papel del Consejo Escolar?

Fuente: Jares [2001, 207-208]

Para encontrar ejemplos muchos más numerosos sobre propuestas prácticas para trabajar actividades sobre Educación en Valores y Educación Intercultural, se recomienda consultar la bibliografía citada a lo largo de este trabajo. 


\section{Bibliografía consultada}

- AULA PRÁCTICA PRIMARIA (2001): Recursos para fomentar los valores. Barcelona, CEAC.

- ARROYO. R. (2000): Diseño y Desarrollo del Curriculum Intercultural: Los Valores Islámicos-Occidentales. Granada, Universidad de Granada.

- AGUADO, M.T. (1997): Educación Multicultural. Su Teorla y su Práctica. Madrid. UNED.

- CID y otros (2001): Valores transversales en la práctica educativa. Madrid, Síntesis.

- ESSOMBA. MA. (Coord.) (1999): Construir la Escuela Intercultural. Barcelona, Graó.

- HERNANDO, M.A. (1997): Estrategias para Educar en Valores. Madrid, CCS.

- JARES, J. (2001): Educación y conflicto. Madrid, Popular.

- JORDAN, J.A. (1996): Propuestas de Educación Intercultural para Profesores. Barclona, CEAC.

- LUCINI. F. (2000): Temas transversales y educación en valores. Madrid, Anaya.

- MEC (1992): Temas Transversales. Educación para la Paz. Madrid, MEC.
- MEC (1996): La Práctica Intercultural en el Desarrollo Curricular de la Educación Primaria. Madrid, MEC.

- PANIEGO, J.A. y LLOPIS, C. (1998): Educar para la Solidaridad. Madrid. CCS.

- PÉREZ SERRANO, G. [1997]. Cómo educar para la democracia. Madrid, Popular.

- REYZÁBAL, M.V. y SANZ, A.I. (1995): Los Ejes Transversales, Escuela Española,

- SÁNCHEZ y otros (2000): "La gestión de los centros desde la perspectiva de la educación intercultural para la paz", en Lorenzo, M. y Ortega, J.A. (coords.): IV Jornadas Andaluzas sobre organización y dirección de instituciones educativas. Universidad de Granada.

- SÁNCHEZ, S. Y MESA, M.C. (2002): Los relatos de convivencia como reaurso didáctico. Elaboración de materiales curriculares como estrategia para la prevención y modificación de estereotipos negativos en contextos multiculturales. Málaga, Aljibe.

- YUS. R. (1996): Temas Transversales: hacia una Nueva Escuela. Graó, Barcelona. 